\title{
Examining usage patterns of a bike-sharing scheme in a medium sized city
}

\begin{abstract}
Bike-sharing is one of the fastest growing new modes of transport in the world, with more and more schemes coming online every year. This paper examines the trends in a bike-sharing scheme that has been in operation in Cork since 2014. While many studies exist on how bike-sharing schemes are changing mobility in cities across the globe, few studies have looked and the dynamics of these schemes in smaller cities. The findings of this research show that in a small compact city like Cork the average trip times recorded are short and regular users have habitual trip patterns using the same bike stations and following similar routes on a daily or weekly basis. The findings also suggest that weather does have an impact upon usage with longer trips more likely during better weather conditions. The findings of the paper provide insights to the dynamics of usage of a smaller bike-sharing scheme and results on how bike-sharing is offering citizens a new transport alternative.
\end{abstract}

\section{Introduction}

Cork Bikes opened in December 2014 with 31 stations and 310 bikes across Cork city. The scheme covers the city covering all of the main trip attractors in the city center including the main train station, the bus station and University College Cork (UCC) (See Figure 1). Cork is the second largest city in the Republic of Ireland and had a population of approx. 120,000 in 2011 (CSO, 2011). Table 1 details the modal split of trips to work or university in Cork City in 2011. This data is taken from the 2011 census of Ireland. The results show that in Cork City that driving to work alone has the largest modal share (45\%) followed by walking $(27 \%)$. Cycling has a smaller modal share in Cork (3\%) however cycling in the city, as with the rest of Ireland, is increasing (Caulfield, 2014). The introduction of the bike scheme in Cork is seen as a policy intervention to increase cycling in the city.

Cite as: Caulfield, B., O’Mahony, M., Brazil, W., Weldon, P. Examining usage patterns of a bike-sharing scheme in a medium sized city, Transportation Research Part A: Policy and Practice, Vol. 100, 2017, pp 152-161 


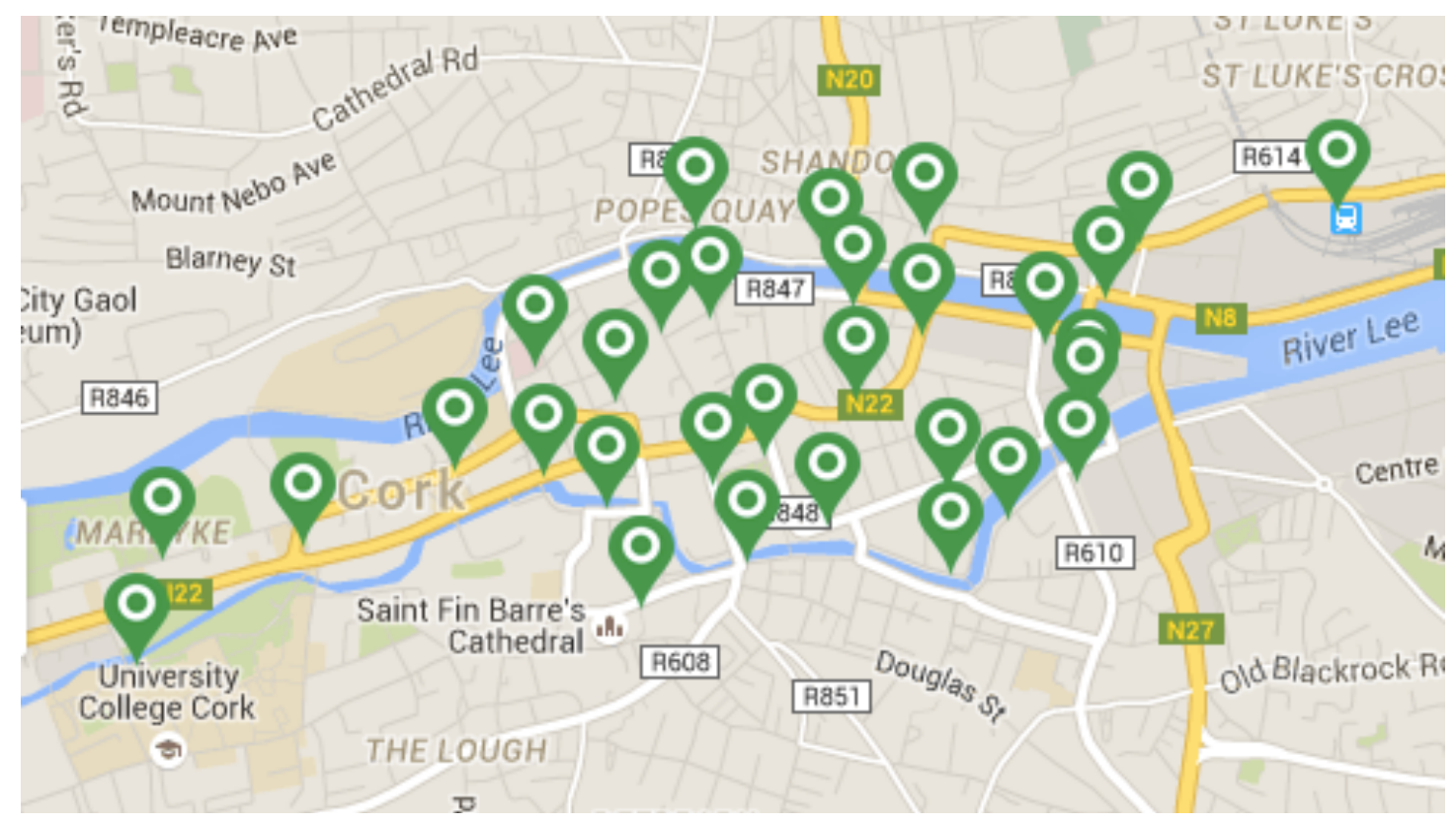

Figure 1: Map of the Cork Bikes scheme

Table 1: Mode share in Cork City (those employed and attending University)

\begin{tabular}{|l|r|r|l|l|}
\hline Mode & $\mathbf{N}$ & \% & $\begin{array}{l}\text { Average travel } \\
\text { time (minutes) }\end{array}$ & $\begin{array}{l}\text { Standard } \\
\text { Deviation of } \\
\text { travel time }\end{array}$ \\
\hline Walking & 13,645 & 27 & 17 & 11.12 \\
\hline Cycling & 1,701 & 3 & 16 & 9.65 \\
\hline Bus & 4,601 & 9 & 30 & 17.55 \\
\hline Rail & 182 & 0 & 47 & 32.41 \\
\hline Motor cycle & 296 & 1 & 17 & 12.33 \\
\hline Driver - alone & 22,330 & 45 & 20 & 14.29 \\
\hline $\begin{array}{l}\text { Drive - } \\
\text { passenger }\end{array}$ & & 18 & 11.72 \\
\hline Van & 3,128 & 6 & & 18.53 \\
\hline Other means & 1,458 & 3 & 24 & 24.61 \\
\hline Work from home & 130 & 0 & 28 & - \\
\hline Not stated & 731 & 1 & - & - \\
\hline Total & 1,790 & 4 & - & - \\
\hline
\end{tabular}

Bike sharing schemes have grown in popularity across the globe in recent years. Much research has been conducted on the bike schemes in larger cities but little has been conducted on schemes in smaller cities like Cork. Table 2 details 48 bikesharing scheme globally with 400 or less bicycles in their current schemes (Bikesharingworld, 2016). The majority of schemes with bike-sharing schemes of a similar size to Cork also have a similar population. Given the number of schemes globally of a similar size, it is important to examine how these schemes work and how users interact with these schemes.

Table 2: International bike-sharing schemes

\begin{tabular}{|l|l|l|l|l|l|}
\hline City & Population & Country & Year opened & Stations & Bicycles \\
\hline Amiens & 133,448 & France & 2008 & 26 & 250 \\
\hline Árhus & 319,680 & Denmark & 2007 & 57 & 400 \\
\hline Austin, Texas & 912,791 & USA & 2013 & 46 & 375 \\
\hline Avignon & 91,283 & France & 2009 & 17 & 200 \\
\hline Batumi & 125,800 & Georgia & 2013 & 22 & 200 \\
\hline
\end{tabular}




\begin{tabular}{|c|c|c|c|c|c|}
\hline Belfast & 333,871 & UK & 2015 & 30 & 300 \\
\hline Belfort & 50,128 & France & 2013 & 21 & 200 \\
\hline Belo Horizonte & $1.4 \mathrm{~m}$ & Brazil & 2014 & 40 & 400 \\
\hline Berlin & $3.5 \mathrm{~m}$ & Germany & 2009 & 50 & 300 \\
\hline Besançon & 116,914 & France & 2007 & 30 & 200 \\
\hline Blackpool & 142,065 & UK & 2009 & 60 & 400 \\
\hline Bucharest & $1.9 \mathrm{~m}$ & Romania & 2008 & 6 & 400 \\
\hline Caen & 108,954 & France & 2008 & 40 & 350 \\
\hline Calais & 72,589 & France & 2010 & 37 & 160 \\
\hline Cergy-Pontoise & 203,913 & France & 2009 & 42 & 320 \\
\hline Charlotte, North Carolina & 792,862 & USA & 2012 & 21 & 200 \\
\hline Chattanooga, Tennessee & 173,366 & USA & 2012 & 33 & 300 \\
\hline Clermont-Ferrand & 141,569 & France & 2013 & 22 & 220 \\
\hline Columbus, Ohio & 822,553 & USA & 2013 & 30 & 300 \\
\hline Copenhagen & 591,481 & Denmark & 2013 & 17 & 250 \\
\hline Cork & 119,230 & Ireland & 2014 & 31 & 330 \\
\hline Dijon & 151,212 & France & 2008 & 39 & 400 \\
\hline Frankfurt am Main & 717,624 & Germany & 2009 & 30 & 300 \\
\hline Galway & 75,530 & Ireland & 2014 & 15 & 195 \\
\hline Girona & 97,227 & Spain & 2009 & 10 & 260 \\
\hline Győr & 128,380 & Hungary & 2015 & 23 & 180 \\
\hline Indianapolis, Indiana & 852,866 & USA & 2014 & 25 & 300 \\
\hline Kansas City, Missouri & 467,007 & USA & 2012 & 30 & 300 \\
\hline Kraków & 759,131 & Poland & 2008 & 34 & 230 \\
\hline La Rochelle & 80,014 & France & $2010^{*}$ & 63 & 300 \\
\hline Lausanne & 133,897 & Switzerland & $2013^{*}$ & 23 & 251 \\
\hline Ljubljana & 277,554 & Slovenia & 2011 & 33 & 215 \\
\hline Limerick & 95,854 & Ireland & 2014 & 23 & 215 \\
\hline Luzern & 78,786 & Switzerland & 2008 & 30 & 280 \\
\hline Madison, Wisconsin & 243,344 & USA & 2011 & 39 & 350 \\
\hline Málaga, Andalucía & 566,913 & Spain & 2013 & 20 & 400 \\
\hline Mulhouse & 111,156 & France & 2007 & 40 & 240 \\
\hline Namur & 110,558 & Belgium & 2012 & 24 & 200 \\
\hline Nancy & 105,421 & France & 2009 & 29 & 250 \\
\hline Nyon, Gland & 29,593 & Switzerland & 2011 & 13 & 167 \\
\hline Opole & 122,120 & Poland & 2012 & 16 & 164 \\
\hline Orléans & 114,167 & France & 2007 & 33 & 300 \\
\hline Palma & 399,093 & Spain & 2011 & 28 & 336 \\
\hline Perpignan & 117,419 & France & 2008 & 15 & 150 \\
\hline Stuttgart & 604,297 & Germany & 2007 & 64 & 400 \\
\hline Tampa, Florida & 347,645 & USA & 2014 & 30 & 300 \\
\hline Valence, Drôme & 62,481 & France & 2010 & 20 & 380 \\
\hline Yokohama & $3.6 \mathrm{~m}$ & Japan & 2011 & 15 & 300 \\
\hline
\end{tabular}

The research objective of this paper is to examine the trends of usage of a bikesharing scheme in a small city. Specifically the research looks at how several factors such as weather conditions, routes, distance travelled and frequency of usage impact upon trip time on the bike-sharing scheme. The research adds to the body of rapidly growing work in this field as it considers the usage of a bike-sharing scheme in a medium sized city.

\section{Literature review}

Numerous concerns regarding the growth of the road transportation sector and climate change have led to the developed interest in sustainable transportation alternatives, and bikesharing (i.e. the shared use of a bicycle fleet which is accessible to the public 
and serves as a form of public transportation (Parkes, et al., 2013)) is emerging as a prominent strategy to assist in addressing concerns such as the usage of clean fuels, transportation demand management, and land use and transportation connection (Shaheen, et al., 2010). As of June 2014, public bike-sharing programmes were incorporated into 712 cities across five continents, comprising approximately 806,200 bicycles at 37,500 stations (Shaheen, et al., 2014). Bike-sharing schemes have evolved over the years, initially consisting of free-to-use bike systems and followed by coin-deposit systems, and the majority of today's bike-sharing schemes are ITbased systems, with some cities incorporating additional functionalities such as demand-responsive and multi-modal systems with real-time information (Shaheen, et al., 2010).

Bikesharing schemes are associated with environmental benefits through the diminished usage of motor vehicles and the associated reduction in fuel use and traffic congestion (Pucher and Buehler, 2005), and in addition to these environmental benefits there have also been numerous social benefits reported through the usage of bikesharing schemes. The American Public Health Association found that the implementation of a public bicycle share programme can lead to greater likelihood of cycling amongst persons living in areas where bike-sharing schemes are available (Fuller, et al., 2013). A survey conducted on users of the bike-sharing programme in Washington, D.C. found that $31.5 \%$ of respondents reported reduced stress and approximately $30 \%$ of individuals stated they had lost weight due to the bike-share system (Alberts, et al., 2012). Bike-sharing has also been associated with an increase in mobility and correlations have been discovered between the close coupling of bikesharing and transit stops with higher usage rates (Nair, et al., 2012).

There are currently four cities in Ireland equipped with bike-sharing facilities, located in Dublin, Cork, Limerick, and Galway cities. There are currently over 100 bike stations in Dublin (with a minimum of 15 stands at each station) and over 1,500 bicycles (dublinbikes, 2016), whilst in Cork there are 31 stations and 330 bicycles (Coca-Cola Zero, 2016). Coca-Cola Zero has entered into partnership with the bikesharing schemes in Ireland, with branding applied to each individual bike in return for investment in the schemes (dublinbikes, 2014). The bike-sharing systems operate on a subscription basis with options available for an annual pass or a three-day pass, and tiered pricing is incorporated based on the duration of a journey made by each bike user, with the first thirty minutes of each journey being free. The Dublinbike scheme is considered one of the most successful bike-sharing schemes in the world (Daly, 2011), with the volume of long-term subscribers surpassing 58,000 by December 2015 and over 3.7 million trips made in 2015 (dublinbikes, 2015).

Due to the potential achievable benefits through the incorporation of bike-sharing schemes in cities there is a growing volume of research into bike-sharing systems. One study focused on understanding the diffusion of public bike-sharing systems in Europe and North America using quantitative and qualitative analyses to explore the reasons for adoption decisions in different cities; it was found that both Europe and North America are experiencing a major adoption phase with new systems emerging and growth in existing systems, and that private sector operators have been important entrepreneurs in both locations with respect to technology and business models (Parkes, et al., 2013). A further study concentrated on the impacts and processes of the implementation and operation of bike-sharing systems and specifically whether 
they are achieving their core objectives; this study found benefits in terms of improved health, increased transport choice and convenience, reduced travel times and costs, and improved travel experience, but concluded that these benefits are unequally distributed since typical users are young males in more advantaged socioeconomic positions. Furthermore, the study states that there is no direct evidence that bike-sharing significantly reduces traffic congestion, carbon emissions, or pollution (Ricci, 2015).

The role of bicycle sharing in an Irish context was studied through a survey analysis, where it was discovered that the bike-sharing scheme in Dublin City: is used predominantly by higher-income individuals; has a different functionality during the peak and off-peak travel times; and has been indirectly successful at improving driver awareness towards cyclists (Murphy and Usher. 2015). A further study focusing on Dublinbikes sought to explain the "ripple effects" associated with the incorporation of a bike-sharing scheme in a city. The study examined a number of domains including rules and regulations, user experiences of navigating the city, the emergence of new factors, the development of infrastructures, and traffic management measures. It was found that the introduction of the Dublin bike-sharing scheme set in motion an array of unpredicted processes and cascade effects, including the generation of new experiences of the city, a greatly increased usage of bicycles in some key areas, economic growth, and shifts in dominant transportation activities (Ó Tuama, 2015).

In a global context, one study focused on mining data from 38 bikesharing systems using an extensive database of the geographical location and bicycle occupancy of each docking station, and analysis was conducted on the variation of occupancy rates over time in order to infer the likely demographics and intentions of user groups. The purpose of the study was to inform operators and policymakers on maintenance, suitable locations for future infrastructure installations, and better targeting of promotional materials to encourage new users (O'Brien, et al., 2014). Data mining was also used in order to analyse operational data from bike-sharing systems to derive bike activity patterns at bike-sharing stations (Vogel, et al. 2011). A further study was concentrated on utilising global bike-sharing data to analyse road safety, where it was discovered that the introduction of a bike-share system is associated with a reduction in cycling injury risk and bike-share users are less likely than other cyclists to sustain fatal or severe injuries (Fishman and Schepers, 2016).

Much of the research conducted to date on bike-sharing schemes tends to take one or more of three general approaches. The approaches typically are:

1. Surveying users of the scheme

2. Data mining of data from online sources of usage at stations

3. Obtaining data from the bike-sharing operator.

Table 2 lists several studies that have examined various aspects of bike-sharing schemes. This list is not meant to be exhaustive; its purpose is to demonstrate the various means of examining bike-sharing as listed above. Table 2 shows that the literature relies on a number different methods of analysis to provide insights into how bike-sharing schemes operate.

Table 2: List of studies 


\begin{tabular}{|l|l|l|l|}
\hline Study & City & $\begin{array}{l}\text { Scheme size (No. } \\
\text { Bikes) }\end{array}$ & Analysis type \\
\hline $\begin{array}{l}\text { O'Neill and Caulfield } \\
(2012)\end{array}$ & Dublin & 550 & $\begin{array}{l}\text { Survey and data } \\
\text { mining }\end{array}$ \\
\hline Fishman et al (2015) & $\begin{array}{l}\text { Melbourne and } \\
\text { Brisbane }\end{array}$ & $\begin{array}{l}600 \text { (Melbourne) 2,000 } \\
\text { (Brisbane) }\end{array}$ & Survey \\
\hline O'Brien et al (2014) & Multiple cities & NA & Data mining \\
\hline O'Tuma (2015) & Dublin & 550 & $\begin{array}{l}\text { Interviews } \\
\text { (survey) }\end{array}$ \\
\hline $\begin{array}{l}\text { De Chardon and } \\
\text { Caruso (2015) }\end{array}$ & Multiple cities & NA & Data mining \\
\hline Zhao et al (2014) & Multiple cities & NA & Data mining \\
\hline Daito and Chen (2013) & Washington D.C. & 2,800 & Full data analysis \\
\hline Tang et al (2011) & Multiple cities & NA & Survey \\
\hline Wang et al (2013 & Minneapolis & 1,550 & Data mining \\
\hline $\begin{array}{l}\text { Hampshire and Marla } \\
\text { (2012) }\end{array}$ & $\begin{array}{l}\text { Barcelona and } \\
\text { Seville }\end{array}$ & $\begin{array}{l}6,000 \text { (Barcelona) 2,100 } \\
(\text { Seville) }\end{array}$ & Data mining \\
\hline Zhao et al (2015) & Nanjing & 1,100 & Full data analysis \\
\hline $\begin{array}{l}\text { Beecham and Wood } \\
\text { (2014) }\end{array}$ & London & 11,500 & Full data analysis \\
\hline $\begin{array}{l}\text { Gebhart and Noland } \\
\text { (2014) }\end{array}$ & Washington D.C. & 2,800 & Full data analysis \\
\hline $\begin{array}{l}\text { Faghih-Imani and } \\
\text { Eluru (2015) }\end{array}$ & Chicago & 3,000 & Full data analysis \\
\hline $\begin{array}{l}\text { Corcoran et al (2014) } \\
\text { Kaplan et al (2015) }\end{array}$ & Brisbane & 2,000 & Full data analysis \\
\hline
\end{tabular}

\section{Overview of the usage of the bike-sharing scheme}

This section of the paper provides an overview of the usage of the scheme during the evaluation period. In this section the data used is detailed, as are some of the usage trends related to the data.

\subsection{Data}

The National Transport Authority (NTA) of Ireland provided the data used in this study. The data is from 2015 and represents the first full year of operation of the Cork Bikes Scheme. The original dataset contained approx. 290,000 trip records. Prior to the evaluation some cleaning of the data was conducted. The first set of data to be removed related to those on temporary passes using the scheme. These were removed as they were considered to be visitors to the city and would not reflect the patterns of native users. This resulted in removing less than 2,000 trip records. The second set of data removed were those trips of less than one minute. These were removed as they were assumed to be trips in which the bike wasn't removed from the station and was just put back once the bike was take out. This resulted in just over 20,000 records being removed from the dataset. The data provided for this research was anonymised so therefore no information on the age or gender of the users was provided. The authors realise this is a limitation of the research, however the findings presented in the subsequent sections do provide several interesting findings on the operation of the bike-sharing scheme.

\subsection{Examining trends in the usage data}


The first set of results presented in this section detail the variables used in subsequent modelling sections and the explanations of these variables are also contained in Table 3. These variables also provide some insight into the usage patterns of the scheme. Travel time is the first variable examined. The results show that the majority of the trips conducted in the scheme are short trips with over $70 \%$ of trips less than 9 minutes. Figure 2 shows the distribution of travel time again showing the amount of short trips that take place in the scheme. As individual identifiers such as age and gender were not available for this study, it was deemed important to find a variable that would show how often people used the scheme. A frequency of usage variable was created to demonstrate how often people used the scheme. The results show that about $18 \%$ of people use the scheme on a daily basis, and almost $60 \%$ of users use the scheme once or twice a week. One of the aspects of the scheme that is examined is how busy the stations are. The busiest stations are categorised as having over 50 trips per-day and the stations with the lowest demand have less than 20 trips per day. The results in Table 3 show that approx. $60 \%$ of all trips originate from the busiest stations in the scheme. The other variables examined that relate to the usage of stations was did the trips from the bike stations have the same origin and destination, the results showed that only $4 \%$ of all trips fell into this category. Another variable examined was the frequency of origin and destination pairs (or routes) within the network. The origin and destination pairs were deemed to be the most popular if over 1,000 trips on these routes were recorded and least popular if less than 500 trips occurred. The results showed that the majority of trips recorded on the least popular routes.

The final set of results examines weather and time of day variables. The results show that over $82 \%$ of trips were recorded on a weekday. The results for time of day show that majority of trips occur in the off peak period from $10 \mathrm{am}-4 \mathrm{pm}$ and in the evening peak between $4 \mathrm{pm}-6 \mathrm{pm}$. Figure 3 details a breakdown of the number of trips taken across the day. A morning and evening peak is apparent as well as a steady usage during the afternoon off-peak period. The rain variable was estimated by taking the average rain fall in Cork over 2015 and estimating did the trips take place in a day above or below this average rain fall of $2.7 \mathrm{~mm}$ of rain. The findings show, as one might expect, more trips took place on days where the rainfall was below average. The other weather variables (temperature and hours of sunshine) were segmented by quartiles so there is more or less an even split between these quartiles. Further interpretation of the impacts of these weather conditions on trips is conducted in section 3.2. The final variable examined is the distance travelled by users of the scheme. This distance is the distance estimated as the distance between bike stations and it is not a distance that is measured by monitoring or tracking cyclists in the network. Therefore the distance may not be accurate but it does give a good indication of distance travelled. The results for distances show that the majority of trips are short trips. This finding corresponds to the travel times recorded.

Table 3: Description of variables used in the MNL model

\begin{tabular}{|l|l|r|r|}
\hline \multirow{4}{*}{ Travel Time } & & $\mathrm{N}$ & $\%$ \\
\cline { 2 - 4 } & Less than 4 mins & 58,417 & 22.3 \\
\cline { 2 - 4 } & $4-6$ mins & 65,300 & 25.0 \\
\cline { 2 - 4 } & $6-9$ mins & 68,494 & 26.2 \\
\cline { 2 - 4 } & Over 9 mins & 69,167 & 26.5 \\
\hline \multirow{2}{*}{ Frequency of usage } & & 47,129 & 18.0 \\
\hline & Every day & 110,547 & 42.3 \\
\cline { 2 - 4 } & At least twice a week & & \\
\hline
\end{tabular}




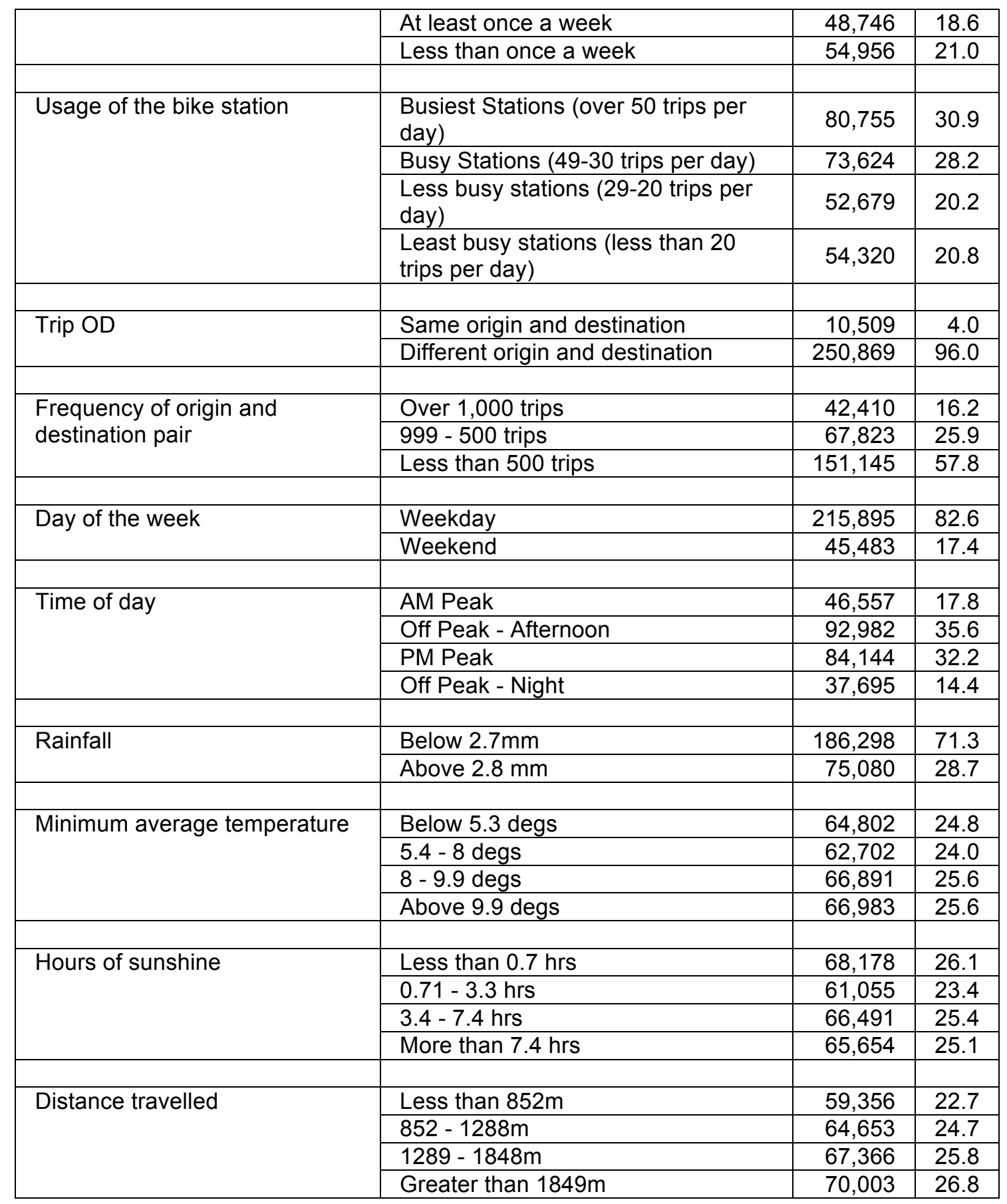




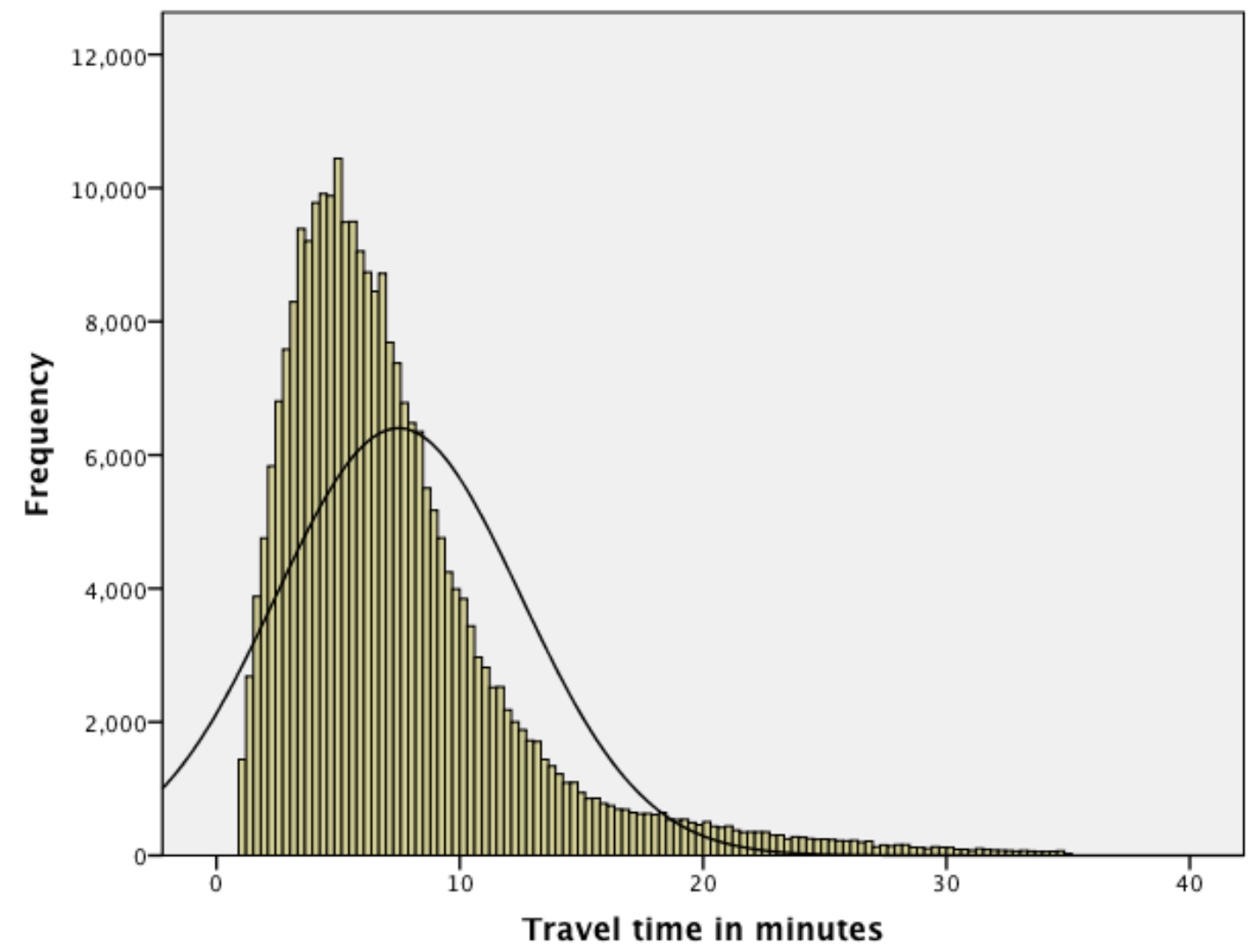

Figure 2: Distribution of travel time 


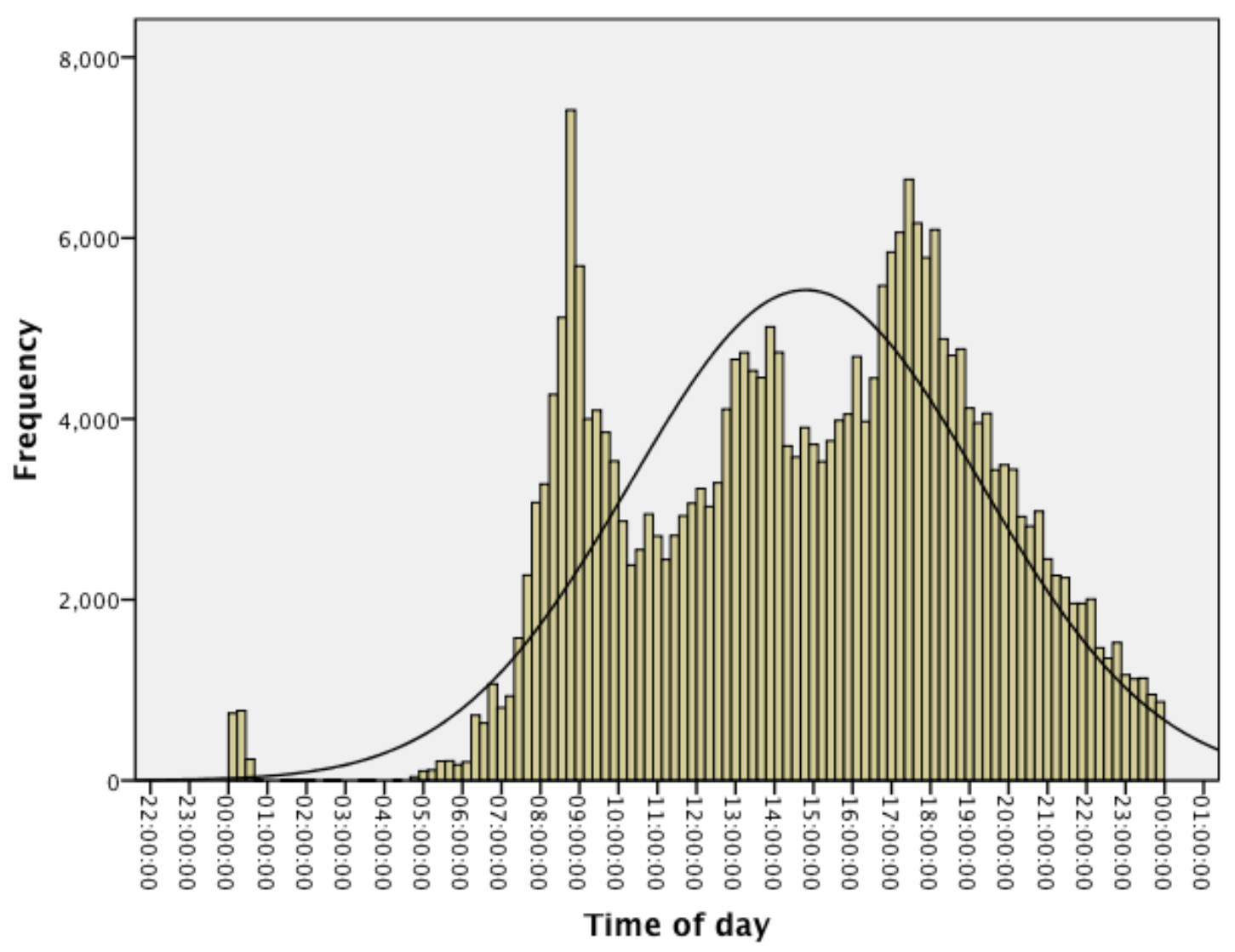

Figure 3: Distribution of rental times

This section of the paper examines some of the usage trends in the data. Table 4 details some of the travel time statistics. The results for the day of the week show an average trip time of 9-10 minutes, this increases to 12-13 minutes at the weekend. The standard deviation and standard error values for the weekend also increase demonstrating a greater degree of variation in travel times at the weekend. The second set of results examines how the frequency of usage impacts upon travel time. The result show that those that use the scheme most have the lowest average travel times and a lower standard deviation and standard error of travel time, compared to those that use the scheme less frequently. The results for the time of day travelled shows that the shortest travel times were recorded in the AM Peak followed by the off-peak nighttime. The final set of results in Table 4 report the travel time for the most popular OD pairs in the network. The findings show that the most popular OD pairs have the lowest average travel time and standard deviation and standard error of travel time. 
Table 4: Examination of Travel time

\begin{tabular}{|l|c|c|c|}
\hline Trips by day of the week & Average travel time & Standard deviation & Standard Error \\
\hline Monday & 9 minutes & 20.9 & .10 \\
\hline Tuesday & 9 minutes & 23.6 & .10 \\
\hline Wednesday & 9 minutes & 18.9 & .08 \\
\hline Thursday & 10 minutes & 24.5 & .11 \\
\hline Friday & 9 minutes & 22.8 & .10 \\
\hline Saturday & 12 minutes & 46.4 & .28 \\
\hline Sunday & 13 minutes & 30.8 & .21 \\
\hline & & & \\
\hline User type & & & .08 \\
\hline Everyday & 8 minutes & 18.6 & .06 \\
\hline At least twice a week & 9 minutes & 20.8 & .11 \\
\hline At least once a week & 10 minutes & 26.7 & .13 \\
\hline Less than once a week & 13 minutes & 38.5 & \\
\hline & & & .07 \\
\hline Time of Day & & & .09 \\
\hline AM Peak & 8 minutes & 17.5 & .07 \\
\hline Off Peak - Afternoon & 11 minutes & 30.0 & .16 \\
\hline PM Peak & 10 minutes & 22.4 & \\
\hline Off Peak - Night & 9 minutes & 32.6 & .05 \\
\hline & & & .09 \\
\hline Frequency of OD pair & & 10.8 & .08 \\
\hline Over 1,000 trips & 8 minutes & 24.7 & \\
\hline 999 - 500 trips & 10 minutes & 30.4 & \\
\hline Less than 500 trips & 11 minutes & & \\
\hline \multicolumn{2}{|l}{}
\end{tabular}

\section{Results, methods and analysis}

\subsection{Modelling approach}

A logistic regression model was used to examine trends within the dataset. The modelling approach uses travel time as segmented into four categories in Table $\mathrm{X}$ as the dependent variable against several independent variables also outlined in Table X. The model takes the following functional form:

$$
\operatorname{logit}(\mathrm{p})=\log \frac{p}{1-p}=a+\beta T+\delta B S+e
$$

where $p$ is the probability that the event occurs, in this case it is that the trip travel time falls into one of the quartiles examined, $\beta T$ is the set of trip characteristics (distance travelled, weather conditions, time of the day, day of the week and frequency of shared bike usage), $\delta B S$ is the set of bike station characteristics (usage of the bike station, trip OD and frequency of origin and destination pair) and $e$ is a random error term.

\subsection{Results of the logistic regression model}

The results of the logistic regression model are presented in Table 4 . The model examines the factors that impact upon trip duration. The Nagelkerke $\mathrm{R}^{2}$ of 0.452 indicates a good model fit. The model provides several interesting insights into the 
usage of the bike sharing scheme in a small city. The first set of results shows that the most frequent users of the scheme are likely to have the shortest journeys. This perhaps suggests that those that use the scheme the most frequently do so for habitual short journeys. Trips from the busiest stations in the scheme were also found to be the shortest trips, this supports the thesis that trips in this scheme are habitual and short. The second set of results that relate to the bike station show that the shortest trips (less than 4 minutes) were likely to be round trips from the same bike station, with longer duration trips likely to have a different origin and destination (as one would expect). The results for frequency of O-D pair (or popularity of a route) shows that the most popular routes have the shortest travel times, this again supports the idea of frequent habitual routes.

The findings also show that shorter trips are likely to take place on weekdays. As one might expect, the results of the rainfall variable show that when rainfall is above average that shorter journeys are more likely. The results for both temperatures an hours of sunshine show that shorter trips are more likely on warmer and brighter days. The final two variables estimated examine how distance and time of day impact upon the travel time. The distance travelled variable, as one would expect, shows that those travelling shorter distances were likely to have the shortest travel times. The final set of variables examined in Table 4 that measure the impact of time of day travelled on trip duration. The findings show that in the morning peak period the shortest trip times were recorded.

The results presented in Table 4 provide a number of interesting findings on travel time on the Cork Bikes scheme. When considering the variables linked to the usage of the stations, the popularity of OD pairs and the frequency of individual usage, the results seem to suggest that the system has a set of regular users that have habitual trips that they take on a daily or at least weekly basis in the network. Further research is needed to determine if these trips are new trips or are these trips as a result of modal shift.

Table 4: Logistic regression model results

\begin{tabular}{|c|c|c|c|c|}
\hline & & $\begin{array}{l}\text { Less than } 4 \\
\text { minutes }\end{array}$ & 4-6 minutes & $\begin{array}{l}6-9 \\
\text { minutes }\end{array}$ \\
\hline & Intercept & $-4.403^{* *}$ & $-2.316^{* *}$ & $-.829^{* *}$ \\
\hline \multirow{4}{*}{$\begin{array}{l}\text { Frequency } \\
\text { of usage }\end{array}$} & Every day & $1.304^{* *}$ & $.803^{* *}$ & $.378^{* *}$ \\
\hline & At least twice a week & $.771^{* *}$ & $.491^{* *}$ & $.302^{* *}$ \\
\hline & At least once a week & $.303^{* *}$ & $.181^{* *}$ & $.186^{\star *}$ \\
\hline & Less than once a week & $0^{\mathrm{b}}$ & $0^{b}$ & $0^{b}$ \\
\hline \multirow{4}{*}{$\begin{array}{l}\text { Usage of } \\
\text { the bike } \\
\text { station }\end{array}$} & $\begin{array}{l}\text { Busiest Stations (over } \\
50 \text { trips per day) }\end{array}$ & $.448^{* *}$ & $.251^{* *}$ & $-.041^{*}$ \\
\hline & $\begin{array}{l}\text { Busy Stations (49-30 } \\
\text { trips per day) }\end{array}$ & $.276^{* *}$ & $.205^{\star *}$ & $.073^{* *}$ \\
\hline & $\begin{array}{l}\text { Less busy stations } \\
\text { (29-20 trips per day) }\end{array}$ & $.014^{* *}$ & $.103^{* *}$ & $-.016^{\star *}$ \\
\hline & $\begin{array}{l}\text { Least busy stations } \\
\text { (less than } 20 \text { trips per } \\
\text { day) }\end{array}$ & $0^{b}$ & $0^{b}$ & $0^{b}$ \\
\hline Trip OD & Same OD & $.093^{* *}$ & $-1.420^{* *}$ & $-1.678^{*}$ \\
\hline
\end{tabular}




\begin{tabular}{|c|c|c|c|c|}
\hline & Different OD & $0^{b}$ & $0^{b}$ & $0^{b}$ \\
\hline \multirow{3}{*}{$\begin{array}{l}\text { Frequency } \\
\text { of OD pair }\end{array}$} & Over 1,000 trips & $.235^{\star \star}$ & $-.061^{*}$ & $.119^{* *}$ \\
\hline & $999-500$ trips & $.085^{\star \star}$ & $.033^{*}$ & $.091^{*}$ \\
\hline & Less than 500 trips & $0^{b}$ & $0^{b}$ & $0^{b}$ \\
\hline \multirow{2}{*}{$\begin{array}{l}\text { Day of the } \\
\text { week }\end{array}$} & Weekday & $.290^{* *}$ & $246^{* *}$ & $179^{* *}$ \\
\hline & Weekend & $0^{b}$ & $0^{b}$ & $0^{b}$ \\
\hline \multirow[t]{2}{*}{ Rainfall } & Below $2.7 \mathrm{~mm}$ & $-.148^{\star *}$ & $-.135^{\star \star}$ & $-.107^{\star \star}$ \\
\hline & Above $2.8 \mathrm{~mm}$ & $0^{\mathrm{b}}$ & $0^{b}$ & $0^{\mathrm{b}}$ \\
\hline \multirow{4}{*}{$\begin{array}{l}\text { Minimum } \\
\text { average } \\
\text { temperature } \\
\text { (degrees }\end{array}$} & Below 5.3 degs & $-.013^{* *}$ & $-.014^{\star *}$ & $-.021^{* *}$ \\
\hline & $5.4-8$ degs & $.094^{* *}$ & $.046^{* *}$ & $.026^{*}$ \\
\hline & $8-9.9$ degs & $.109^{* *}$ & $.093^{* *}$ & $.087^{* *}$ \\
\hline & Above 9.9 degs & $0^{b}$ & $0^{b}$ & $0^{\mathrm{b}}$ \\
\hline \multirow{4}{*}{$\begin{array}{l}\text { Hours of } \\
\text { sunshine (in } \\
\text { hours) }\end{array}$} & Less than $0.7 \mathrm{hrs}$ & $.102^{\star *}$ & $.148^{\star \star}$ & $.099^{*}$ \\
\hline & $0.71-3.3 \mathrm{hrs}$ & $.104^{* *}$ & $.095^{\star *}$ & $.067^{* *}$ \\
\hline & $3.4-7.4 \mathrm{hrs}$ & $.229^{\star *}$ & $.330^{* *}$ & $.234^{*}$ \\
\hline & More than $7.4 \mathrm{hrs}$ & $0^{\mathrm{b}}$ & $0^{b}$ & $0^{\mathrm{b}}$ \\
\hline \multirow{4}{*}{$\begin{array}{l}\text { Distance } \\
\text { travelled } \\
\text { (meters) }\end{array}$} & Less than $852 \mathrm{~m}$ & $5.363^{* *}$ & $2.341^{* \star}$ & $-.030^{\star *}$ \\
\hline & $852-1288 m$ & $4.596^{* *}$ & $3.239^{\star *}$ & $1.029^{* *}$ \\
\hline & $1289-1848 m$ & $2.224^{* *}$ & $2.074^{\star *}$ & $1.251^{* *}$ \\
\hline & Greater than $1849 \mathrm{~m}$ & $0^{\mathrm{b}}$ & $0^{b}$ & $0^{b}$ \\
\hline \multirow{4}{*}{ Time of day } & AM Peak & $.584^{\star *}$ & $.379^{* *}$ & $262^{* *}$ \\
\hline & Off Peak - Afternoon & $-.608^{* *}$ & $-.379^{\star \star}$ & $-.190^{\star *}$ \\
\hline & PM Peak & $-.576^{* *}$ & $-.354^{\star \star}$ & $-.135^{\star *}$ \\
\hline & Off Peak - Night & $0^{b}$ & $0^{b}$ & $0^{\mathrm{b}}$ \\
\hline \multicolumn{4}{|l|}{$\mathrm{N}$} & 261,378 \\
\hline \multicolumn{4}{|c|}{-2Log-likelihood at convergence } & 14344.080 \\
\hline \multicolumn{4}{|c|}{ Nagelkerke $\mathrm{R}^{2}$} & .452 \\
\hline \multicolumn{4}{|c|}{ Chi-squared statistic } & 11359.358 \\
\hline \multicolumn{4}{|c|}{ Degrees of freedom } & 69 \\
\hline
\end{tabular}

\section{Conclusions}

As discussed in this paper bike-sharing is growing rapidly around the world. Bikesharing, is one of the fastest growing modes of shared mobility globally, and is changing attitudes to cycling and sharing transport infrastructure. This paper provides details of one of the most recently launched bike-sharing schemes in Ireland. The results show that even though Cork would not have been a city with a strong cycling culture, that the scheme is being used frequently.

One of the key things this paper considered was usage patterns within the bikesharing scheme. The findings show that the majority of trips in the scheme were short and in most cases frequent trips. Frequent users of the scheme were shown to have the shortest travel times, suggesting that these users have incorporated the scheme in to their daily (or weekly) trips. Weather conditions were also found to have an impact upon usage of the scheme. During good weather conditions the number of trips and the travel time was shown to be greater. 
The findings of this paper do provide valuable insights as to how a bike-sharing scheme works in a small city. More research is needed on these smaller schemes to understand how the dynamics of the schemes differ from those schemes in larger cities like New York and London. The findings also inform discussion on schemes in even smaller cities, given that the results found in Cork show very small trip times, would this mean that in even smaller cities trip times would be smaller.

\section{Acknowledgements}

The authors would like to thank the National Transport Authority for access to the Cork Bike dataset.

\section{References}

Zhao, J., Wang, J., Deng, W. Exploring bikesharing travel time and trip chain by gender and say of the week. Transportation Research Part C: Emerging Technologies, Volume 58, Part B, September 2015, Pages 251-264

Zhao, J., Deng, W., Song, Y. Ridership and effectiveness of bikesharing: The effects of urban features and system characteristics on daily use and turnover rate of public bikes in China. Transport Policy, Volume 35, September 2014, Pages 253-264

de Chardon, C.M., Caruso, G. Estimating bike-share trips using station level data. Transportation Research Part B: Methodological, Volume 78, August 2015, Pages 260-279

O'Brien, O., Cheshire, J., Batty, M. Mining bicycle sharing data for generating insights into sustainable transport systems. Journal of Transport Geography, Volume 34, January 2014, Pages 262-273

Ricci, M. Bike sharing: A review of evidence on impacts and processes of implementation and operation. Research in Transportation Business \& Management, Volume 15, June 2015, Pages 28-38

Fishman, E., Washington, S., Haworth, N., Watson, A. Factors influencing bike share membership: An analysis of Melbourne and Brisbane. Transportation Research Part A: Policy and Practice, Volume 71, January 2015, Pages 17-30

O'Neil, P., Caulfield, B. Examining user behaviour on a shared bike scheme: the case of Dublin Bikes, The 13th International Conference on Travel Behaviour Research, Toronto , 2012

O'Tuama, D. Ripples through the city: Understanding the processes set in motion through embedding a public bike sharing scheme in a city. Research in Transportation Business \& Management, Volume 15, June 2015, Pages 15-27 
Daito, N., Chen, Z. Demand of Bike Sharing Travels: Evidence from Washington D.C. Transportation Research Board $92^{\text {nd }}$ Annual Meeting, 2013, Washington D.C.

Tang, Y., Pan, H., Shen, Q. Bike-sharing Systems in Beijing, Shanghai and Hangzhou and their impact on travel behavior. Transportation Research Board $90^{\text {th }}$ Annual Meeting, 2011, Washington D.C.

Wang, X., Lindsey, G., Schoner, J.E., Harrison, A. Modeling bike share station activity: the effects of nearby businesses and jobs on trips to and from stations. Transportation Research Board $92^{\text {nd }}$ Annual Meeting, 2013, Washington D.C.

Hampshire, R.C., Marla., L. An analysis of bike sharing usage: explaining trip generation and attraction from observed demand. Transportation Research Board $91^{\text {st }}$ Annual Meeting, 2012, Washington D.C.

Beecham, R., Wood, J. Characterising group-cycle journeys using interactive graphics. Transportation Research Part C: Emerging Technologies, Volume 47, Part 2, October 2014, Pages 194-206

Fishman, E. Bikeshare: A review of recent literatue. Transport Reviews, Volume 36, Issue 1, 2016.

Corcoran, J., Li, T., Rohde, D., Charles-Edwards, E., Mateo-Babiano, D. Spatiotemporal patterns of a public bike sharing program: the effect of weather and calendar events. Journal of Transport Geography, Volume 41, December 2014, Pages 292-305

Kaplan, S., Manca, F., Nielsen, T., Prato, C. Intentions to use bike-sharing for holiday cycling: An application of the theory of planned behavior. Tourism Management, Volume 47, April 2015, Pages 34-46

Parkes, S.D., Marsden, G., Shaheen, S.A., Cohen, A.P. Understanding the diffusion of public bikesharing systems: evidence from Europe and North America. Journal of Transport Geography, Volume 31, July 2013, Pages 94-103

Faghih-Imani, A., Eluru, N. Analysing bicyle-sharing system user destination choice preferences: Chicago's Divvy system. Journal of Transport Geography, Volume 44, April 2015, Pages 53-64

Gebhart, K., Noland, B. The impact of weather conditions on bikeshare trips in Washington, D.C. Transportation, November 2014, Volume 41, Issue 6, pp 1205 1225 